\title{
Operational Planning of Supply Chains in a Production and Distribution Center with Just-in-time Delivery
}

\author{
Pablo Biswas ${ }^{1}$ (iD), Bhaba Sarker ${ }^{2}$ (iD \\ ${ }^{1}$ Mercer University (United States) \\ ${ }^{2}$ Louisiana State University (United States) \\ biswas_p@mercer.edu,bsarker@lsu.edu
}

Received: October 2019

Accepted: April 2020

\begin{abstract}
:
Purpose: $A$ supply chain consists of raw material suppliers, manufacturers and retailers where inventory of raw materials and finished goods are involved, respectively. Therefore, it is important to find optimal solutions, which are beneficial for both supplier, manufacturer and retailer.

Design/methodology/approach: This research focuses on a semi-continuous manufacturing facility by assuming that the production of succeeding cycle starts immediately after the production of preceding cycle. In reality, the inventory of a supply chain system may not be completely empty. A number of products may be left over after the deliveries are made. These leftover inventories are added to the next shipment after the production of required amount to make up a complete batch for shipment. Therefore, it is extremely important to search for an optimal strategies for these types production facilities where leftover finished goods inventory remains after the final shipment in a production cycle. Considering these scenarios, an inventory model is developed for an imperfect matching condition where some finished goods remains after the shipments.
\end{abstract}

Findings: Based on the previous observation, this research also considers a single facility that follows JIT delivery and produces multiple products to satisfy customers' demand. For this problem a rotational cycle model is developed to optimize the facility operations. Both problems are categorized as mixed integer non-linear programming problems which are to be solved to find optimum number of orders, shipments and rotational cycle policy for multiple products. Also, this solution will lead to estimate the optimum production quantity and minimum total system cost.

Research limitations: This research considers the supply chain based on manufacturers point of view and it does not consider the transportation cost associated with supply chain. Next study will be focused on issues with joint decision making, information sharing, and transportation decision.

Practical implications: This study will help the managers of refinery and paper industries in making their operation smooth by applying optimizing techniques and robust decision making.

Originality/value: Based on the literature, no research was found on continuous production system supply chain and its optimization with JIT delivery. This research will definitely provide a direction for such problem to the researchers.

Keywords: supply chain system, just-in-time delivery, initial inventory, minimum idle time and rotational cycle policy 


\section{To cite this article:}

Biswas, P., \& Sarker, B. (2020). Operational planning of supply chains in a production and distribution center with just-in-time delivery. Journal of Industrial Engineering and Management, 13(2), 332-351. https://doi.org/10.3926/jiem.3046

\section{Introduction}

Generally, Just-in-time (JIT) production systems have zero inventory systems and no buffer. In 1992, Golhar and Sarkers' observation stated that participation in JIT delivery system is economically disadvantageous for suppliers (Golhar \& Sarker, 1992). In JIT system, the supplier has to coordinate his production with the buyer's demand so as to maintain zero inventory, but, in reality the supplier ends up with carrying large inventories to deliver limited shipments. In their work, an iterative solution is proposed to minimize the generalized total inventory cost model which is a piecewise convex function. Sarker and Parija (1994) developed a more general problem, which considered both supplier and buyer to determine optimal ordering policy for the raw material and manufacturing batch size to minimize the total cost. They also considered that, at the end of the delivery, a few finished goods are left over which is less than the shipment amount. They solved the problem in semi-closed form and found that the total cost function is piecewise convex. Figure 1 represents a typical supply chain operating under JIT delivery.

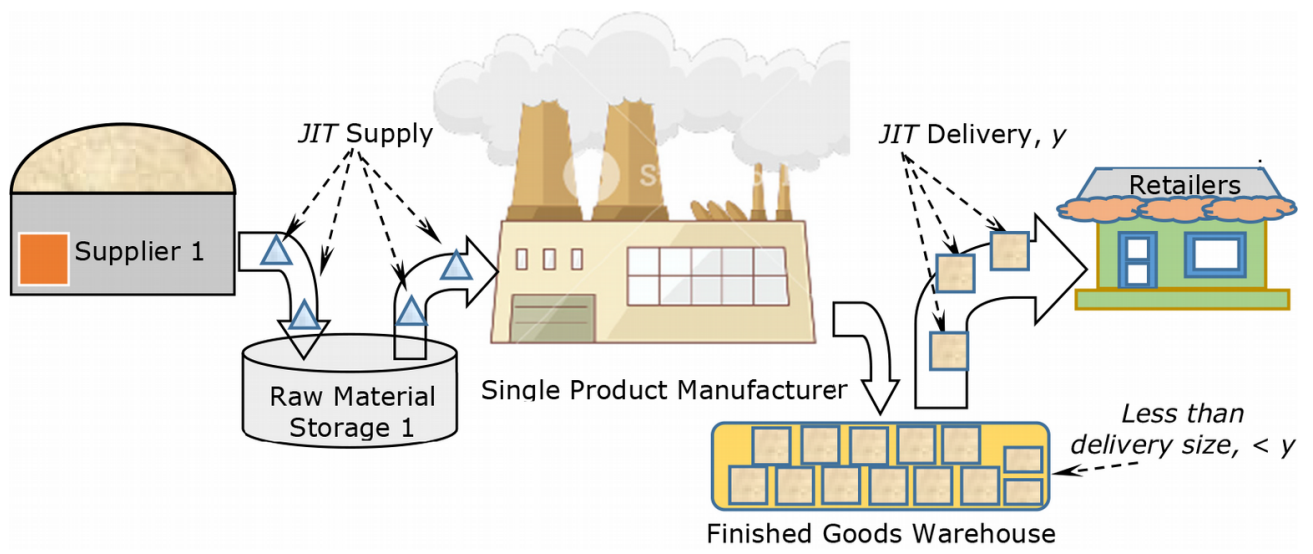

Figure 1. A typical JIT operated supply chain model with imperfect matching inventory

Hill (1996) modified the raw material ordering policy of Sarker and Parija (1994) by allowing a single order for multiple production cycles when the inventory cost for the raw material is much lower as compared to the ordering costs in each production cycle. Sarker and Khan (1999) proposed an ordering policy for raw materials to meet the requirements of a production facility that must deliver finished goods according to customers' demand at a fixed point of time. They considered that the products were supplied after processing the entire lot and quality certification of the products. They also evaluated relationships between production batch size, raw material quantity and delivery patterns. Biswas and Sarker (2005) studied a semi-continuous production system with JIT delivery and supply, where they proposed a total cost function of the system minimizing the downtime of the production facility and solved the problem with an integer approximation.

Sarker and Khan (1999) proposed an ordering policy for raw materials to meet the requirements of a production facility that must deliver finished goods according to customers' demand at a fixed point of time. They considered the finished products were supplied after processing the entire lot and quality certification and with just in time delivery. They evaluated relationships between production batch size, raw material quantity and delivery patterns. Few years later, Khan and Sarker (2002) developed another model for a manufacturing system which procures raw material from the suppliers in a lot and processes them as finished products. They estimated production batch sizes 
for a JIT delivery system and incorporated a JIT raw material supply system. Diponegoro and Sarker (2002) developed a decision rule for the manufacturer to determine the delivery quantities, the production start time and batch sizes with trend demands during increasing, level and declining phases of the life cycle of a product. Chiu and Huang (2003) proposed an integrated just-in-time (JIT) inventory model of a multi-echelon with random delivery lead times for a serial supply chain with information exchange between members to make purchase, production, and delivery decisions jointly. The authors proposed search method for finding the optimal solution. Kim, Hong and Lee (2005) discussed the production and ordering policies of a single-manufacturer and single-retailer supply chain where retailer places orders based on the EOQ-like policy, and the manufacturer procures raw materials and distributes them to the multiple plants in parallel to satisfy retailer's demand. They proposed an efficient and effective heuristic algorithm to determine the near-optimal production allocation ratios. Diponegoro and Sarker (2006) developed an ordering policy for raw materials and determined an economic batch size for a product in a manufacturing system that supplies finished products to customers for a finite planning horizon. They considered the JIT delivery policy with lost sale problem due to shortage. Kim, Banerjee and Burton (2008) examined the relationship benefits of buyer-supplier over lot-for-lot with single setup single delivery systems. Also, they suggested two policies so that the supplier can satisfy customers' demand with single setup multiple delivery, multiple setup multiple delivery. Diponegoro and Sarker (2007) studied an operational policy for a lean supply chain system consisting of a manufacturer, multiple suppliers and multiple buyers. He dealt with three interrelated problems in supply chain. They are (a) single supplier and single buyer with fixed delivery size, (b) multiple suppliers and multiple buyers with individual delivery schedule and (c) time dependent delivery quantity with trend demand. He formulated these problems as mixed-integer, nonlinear programming problems with discrete, non-convex objective functions and constraints. Diponegoro and Sarker (2007) also developed a closedform heuristic which provided near optimal solutions and tight lower bounds.

Hoque (2009) considered the single-vendor single-buyer integrated production inventory problem where the lot is transferred by some researchers in shipments of equal and/or unequal sizes. The author demonstrated that the minimal number $(m)$ of unequal sized shipments selected might not be the minimal and developed a method for obtaining the minimal $m$ and total number (n) of shipments. Mungan, Yu and Sarker (2010) developed an integrated inventory model for high-tech industries in JIT environment under continuous price decrease over finite planning horizon. They modelled an efficient algorithm to minimize the total cost of the system by determining optimal lot sizes for raw material procurement, and manufacturing batch under a finite planning horizon. Jha and Shanker (2009) presented a single-vendor single-buyer system-based production-inventory model for decaying items which deplete with constant decay rate. They formulated the model to find the optimal order quantity, lead time and the number of shipments from the vendor to the buyer during one production cycle which minimizes the total system cost. Sarker and Diponegoro (2009) addressed an optimal policy for production and procurement in a supply-chain system with multiple non-competing suppliers, a manufacturer and multiple non-identical buyers where the demand of finished product is given by buyers and the shipment size to each buyer is fixed. Chen and Sarker (2010) proposed a multi-vendor optimal model for deciding the batch size of vendor's production, and delivery frequencies of different vendors to the manufacturer including shared transportation costs.

Hoque (2011) developed a generalized single-vendor multi-buyer supply chain model by synchronizing both the single-vendor single-buyer and the single-vendor multi-buyer integrated inventory supply chains by transferring the lot either only with equal-sized or only with unequal-sized sub-lot (batches) and presented logical development of their minimal cost solution techniques. Mansouri, Gallear and Askariazad (2012) aimed to identify the gaps in decision-making support based on multiobjective optimization (MOO) for build-to-order supply chain management available in the literature. Sana (2012) investigated an economic order quantity/ economic production quantity model in three-layer (manufacturer, vendor and retailer) supply chain management with defective quality items while production rate, order quantity, number of shipments with equal sizes. Jonrinaldi and Zhang (2013) proposed a model and solution method for coordinating integrated production and inventory cycles in a whole manufacturing supply chain involving reverse logistics for multiple items with finite horizon period. The authors considered just in time delivery at the distributor's end to the retailers. 
Modak, Panda and Sana (2015) studied a just-in-time based defective manufacturing environment including preventive maintenance. They incorporated just-in-time buffers for both the perfect and imperfect quality items to continue the normal operation during the shutdown period and optimized the just-in-time buffer to minimize the system running cost. Omar and Sarker (2015) considered a just-in-time (JIT) manufacturing system to synchronize JIT purchasing and selling in small lot size as a means of minimizing the total supply chain cost. The authors proposed an optimal policy where the shipment intervals as well as the lot sizes are varied. Fandel and Trockel (2016) focused on lot size planning of a two-firm supply chain expansion to include investment decisions and to coordinate the just-in-time-delivery with the lot size planning on the basis of the Harris- or the Wagner/Whitin-approach, which resulted the disposition benefits by Wagner/Whitin led to dominant solutions. Torkabadi and Mayorga (2017) considered on the implementation of Just-In-Time (JIT) in a multi-stage, and multi-product supply chain with Kanban, ConWIP, and a hybrid PCP. Considering the uncertainty, the authors evaluated performances of policies via a Fuzzy AHP method.

Wang and Ye (2018) studied the Just in time (JIT) and Economic order quantity (EOQ) models with carbon emissions in a two-echelon supply chain with single manufacturer and $n$ retailers. In their model, they proposed that the manufacturer and retailers could adopt either a JIT mode or an EOQ mode in which every retailer could decide its own optimal lot size. Kim and Shin (2019) proposed that the third-party logistics service provider would determine the optimal order quantity, considering defective items under the VMI and JIT conditions. They designed a mathematical decision-making problem based on the EPQ /EOQ with defective items, which provides the optimal order quantity for TPL service providers under VMI and JIT. Mardani, Kannan, Hooker, Ozkul, Alrasheedi and Tirkolaee (2020) presented a comprehensive review of the application of the Structural Equation Modelling (SEM) in the assessment of sustainable and green supply chain management (SCM) where these were systematically identified, reviewed, and categorized the SEM in the field of green SCM. Nobil, Sedigh and Cárdenas-Barrón (2020) developed a multiproduct economic production quantity inventory model for a vendorbuyer system in which several products are manufactured on a single machine and vendor delivers the products to customer in small batches. The aim of this study was to determine the optimal cycle length and the number of delivered batches for each product so that the total inventory cost is minimized.

During the model development, all of the researchers (Chen \& Sarker, 2010; Mungan et al., 2010; Hoque, 2009; Diponegoro \& Sarker, 2002, 2006, 2007; Sarker \& Diponegoro, 2006, 2009; Sarker \& Parija, 1994; Parija \& Sarker, 1999; Khan \& Sarker, 2002; Wang \& Ye, 2018; Kim \& Shin, 2019; Mardani et al., 2020) considered that the system remains idle until the shipments are made. Figure 2 shows the production with just-in-time (JIT) delivery.

In reality, the inventory of a supply chain system never becomes empty. A number of products are always left-over after the deliveries are made. These left-over amounts are added to the next shipment after the production of required amount to make-up a complete batch. An illustration may be observed in car manufacturing company such as Toyota, Honda, etc. where the new model cars go in production before the old model cars inventory runs out. Large industries (refineries, paper mills, etc.) also start their production before the finished product inventories fall to zero. Therefore, it is important to search for an optimal supply chain system for these kinds production facilities with left-over finished goods inventory. This research also focuses on the issue of minimizing the idle time of the production system. Based on the inventory decisions, the supply chain system of the production facility with JIT operation is discussed in the current research. A production facility (such as refinery, aluminium conversion industry) produces multiple products from a single type raw material (crude oil, large aluminium sheets, among others) and shipped to customers according to their demand. In the supply chain system of these categories of production facilities, the raw materials are ordered from the suppliers, and process the raw material into multiple finished products and deliver to the buyers or retailers. A single facility supply chain system is represented in Figure 1. For the last few decades, just-in-time (JIT) philosophy has played an important role in supply chain systems such as the manufacturing sectors. The successful implementations of JIT phenomena are frequent shipment of high-quality parts to the buyers and ordering raw materials in small batches whenever required to process finished products. 


\section{Problem Identification}

When the production run stops, the on-hand inventory stops building up. Finished goods may be adequate for shipments after the production run is over as represented in Figure 1. In reality, the last shipment size may be less than the required amount. This situation leads to an imperfect matching. In this part of the research, the function is developed to find economic order quantity $(E O Q)$ for the raw materials and an economic manufacturing quantity $(E M Q)$ for the production facility with imperfect matching and minimal idle time. Here, raw material ordering cost, raw material inventory cost, manufacturing setup cost and finished goods inventory carrying cost are considered. In this section, an expression for the generalized cost function is developed that may be used to determine an optimal batch quantity for the production run.

\subsection{Notation}

To develop the model for determining the interactions between raw materials and finished goods demand, following definitions and notation are used:

$C_{O} \quad=$ ordering cost of raw material, $\$$ /order;

$C_{S} \quad=$ manufacturing setup cost, $\$ / \mathrm{batch} ;$

$h_{M} \quad=$ holding cost of finished goods, $\$ /$ unit/year;

hs $\quad=$ holding cost of raw material, $\$ /$ unit/year;

$D_{M} \quad=$ demand for finished goods, units/year;

$D_{S} \quad=$ demand for raw materials, units/year;

$f \quad=$ conversion factor of the raw materials; $f=D_{M} / D_{S}=Q_{M}^{\prime} / Q^{\prime}$;

$L \quad=$ interval between deliveries, in years; $L=y / D_{M}$;

$m \quad=$ number of full shipments of finished goods per cycle time;

$n \quad=$ number of orders for raw materials; $m \geq n \geq 1$;

$P_{M} \quad=$ production rate, units/year;

$Q^{\prime}{ }_{M} \quad=$ quantity of finished goods manufactured per setup, units $/ \mathrm{batch}$;

$Q_{S}^{\prime} \quad=$ quantity of raw materials required for each batch; $Q^{\prime}{ }_{S}=Q^{\prime}{ }_{M} / f$;

$I_{I M} \quad=$ total finished goods inventory for imperfect matching, units;

$I_{I S} \quad=$ total raw materials inventory, units;

$I_{0} \quad \quad=$ quantity remained after the $m$ number of shipments, or initial inventory, units;

$T^{\prime} \quad=$ total cycle time, years;

$T_{1} \quad=$ production time (uptime), years; $T_{1}=Q^{\prime}{ }_{M} / P_{M}=\left(m y+I_{0}\right) / P_{M}$;

$T_{2} \quad=$ pure consumption time, years (downtime);

$T_{S} \quad=$ setup time, years; $T_{S}<L ;$

$T C_{I M} \quad=$ total cost of finished goods, $\$ /$ year;

$T C_{I S} \quad=$ total cost of raw materials, $\$ /$ year;

$T C_{I}\left(Q_{M}^{\prime}, n\right)=$ total cost function for imperfect matching, $\$ /$ year;

y $\quad=$ amount of finished goods shipped per time L, units/shipment.

\subsection{Assumptions}

To develop the mathematical model few important assumptions are:

1. Production rate is constant and finite and is greater than the demand rate.

2. Supply chain of the system considers JIT delivery and supply of finished goods and raw materials, respectively.

3. There is only one manufacturer and one raw material supplier.

4. A fixed quantity is left-over after required shipments and carried over to the succeeding cycle.

5. Production run of following cycle starts after the uptime of previous cycle and setup time. 


\subsection{Formulation of Cost Function Based on Average Inventory}

In this case, the production rate, $P$, is assumed to be greater than the demand rate, $D_{M}$, so that there should be an inventory build-up during the production. Figure 2 shows the inventory build-up, where Figure 2(a) represents the inventory of the raw material supply and Figure 2(b) denotes the on-hand inventory of finished goods. Also, Figure 2(b) has an initial inventory, $I_{0}$ units, remaining at the end of $m$ full shipments. That amount remained in cycle 1 is carried over to the start of the production uptime of cycle 2 , and amount remaining at cycle 2 is carried over till the end of cycle 3 , and so forth. Here, production starts after $T_{S}$ time units and produces exactly $Q_{F}^{\prime}\left(=m y+I_{0}\right)$ amount to deliver $y / 2$ after $L$ time units. Hence, during time $L-T_{S}$ time the quantity produced is $y / 2-I_{0}$ at the rate of $P$, so that $I_{0}+\left(y / 2-I_{0}\right) P_{M} \geq y / 2$. Figure 1 is used to calculate the average on-hand inventory of the finished goods.

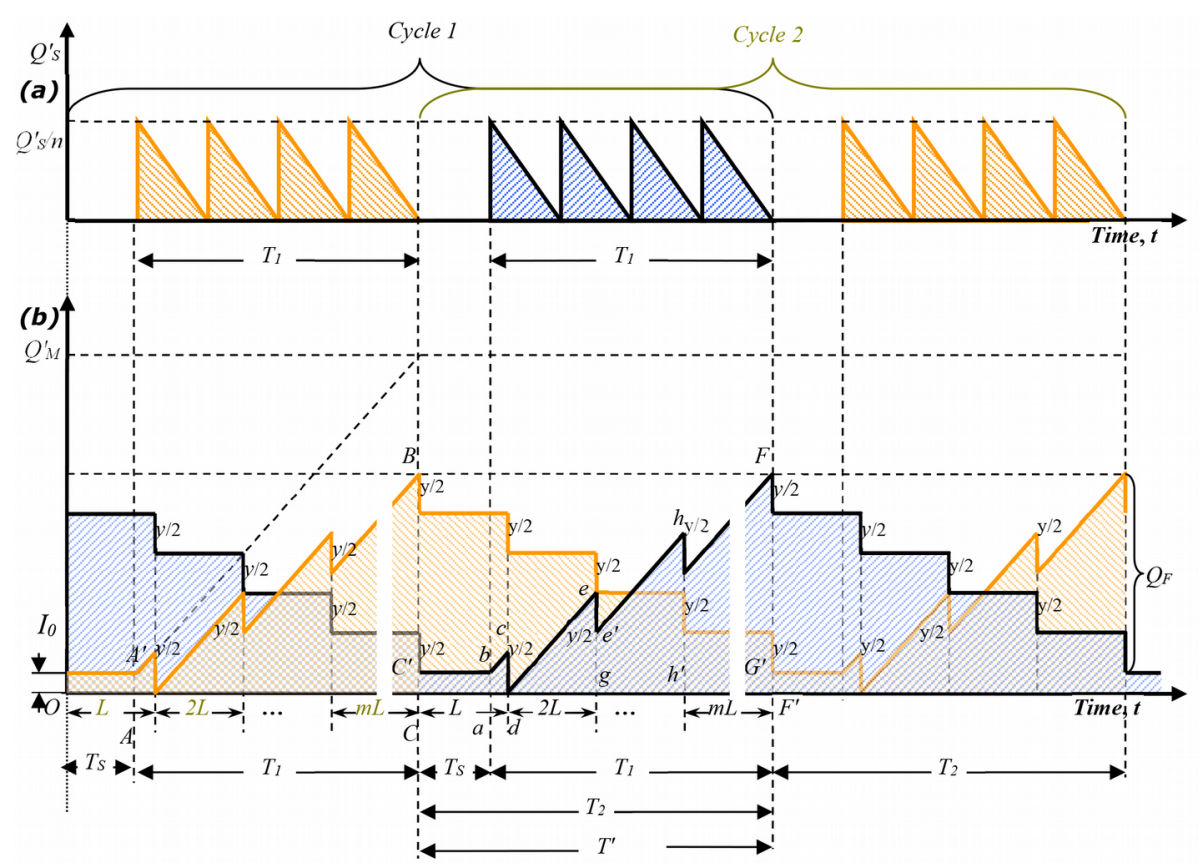

Figure 2. (a) Raw material inventory; (b) Finished goods inventory

$\hat{I}_{I M}, \hat{I}_{I P}$, and $\hat{I}_{I D}$ are the total inventory, uptime inventory and downtime inventory for the imperfect matching, respectively. Therefore, the total inventory can be calculated as

$$
\hat{I}_{I M}=\hat{I}_{I P}-\hat{I}_{I D}
$$

From Figure 1, it can be found that

$$
\hat{I}_{I P}=\text { area } C^{\prime} b a c+\text { area } a b c d+\Delta d e g+\text { area } g e^{\prime} h F F^{\prime},
$$

Therefore, the total produced inventory can be found as

$$
\hat{I}_{I P}=\frac{m y}{2} T_{1}+\frac{m y}{2} T^{\prime}+2 I_{0} T^{\prime}
$$

Again, the total inventory shipped can be calculated from Figure 2(a) as

$$
\begin{aligned}
\hat{I}_{I D}=L(y / 2)+2 L(y / 2)+\ldots & +(m-1) L(y / 2)+L(y / 2)+2 L(y / 2)+ \\
\ldots+ & +(m-1) L(y / 2)=2 \frac{m(m-1)}{2} \frac{y L}{2}=\frac{m y^{2}}{2 D_{M}}(m-1),
\end{aligned}
$$

where $L=y / D_{M}$.

Hence, the total inventory for time period, $T^{\prime}$, can be calculated by combining Equations (3) and (4) as 


$$
\hat{I}_{I M}=\frac{Q_{M}^{\prime 2}}{2 D_{M}}+\frac{Q_{M}^{\prime}}{2 D_{M}}\left(4 I_{0}+y-D_{M} T_{S}\right)+\frac{I_{0}}{2 D_{M}}\left(D_{M} T_{S}-I_{0}-y\right),
$$

where $T^{\prime}=\mathrm{Q}_{M}^{\prime} / D_{M}$ and $\mathrm{Q}_{M}^{\prime}=m y+I_{0}$.

Again, the total cycle time for imperfect matching case can be calculated as

$$
T^{\prime}=Q_{M}^{\prime} / D_{M}
$$

Hence, the average inventory for imperfect matching case is

$$
\begin{aligned}
\overline{\hat{I}}_{I M}=\frac{\hat{I}_{I P}+\hat{I}_{I D}}{T^{\prime}} & =\frac{D_{M}}{Q_{M}^{\prime}}\left[\frac{Q_{M}^{\prime 2}}{2 D_{M}}+\frac{Q_{m}^{\prime}}{2 D_{m}}\left(4 I_{0}+y-D_{M} T_{S}\right)-\frac{I_{0}}{2 D_{M}}\left(I_{0}+y-D_{M} T_{S}\right)-\right. \\
& =\frac{Q_{M}^{\prime}}{2}-\frac{I_{0}}{2 Q_{M}^{\prime}}\left(I_{0}+y-D_{M} T_{S}\right)+\frac{1}{2}\left(4 I_{0}+y-D_{M} T_{S}\right) .
\end{aligned}
$$

Therefore, the total cost function for the finished products can be written as

$$
\begin{aligned}
T C_{I M} & =\frac{D_{M}}{Q_{M}^{\prime}} K_{S}+\overline{\hat{I}}_{I M} H_{M} \\
& =\frac{D_{F}}{Q_{F}^{\prime}} K_{S}+H_{F}\left[\frac{Q_{F}^{\prime}}{2}-\frac{I_{0}}{2 Q_{F}^{\prime}}\left(I_{0}+x-D_{F} T_{S}\right)+\frac{1}{2}\left(4 I_{0}+x-D_{F} T_{S}\right) .\right.
\end{aligned}
$$

During the production time or uptime, $T_{1}$, the raw materials are ordered to produce finished products, which require $Q^{\prime}$ units of raw materials to produce $Q^{\prime}{ }_{M}$ units of finished goods and they are instantaneously replenished by the outside supplier in $n$ batches. Also, $f$ units of raw materials required to produce one unit of finished product, i.e., $f Q_{s}=Q_{M}$. As a result, raw materials inventory of entire cycles can be expressed as

$$
\bar{I}_{I S}=\left(\frac{Q_{S}^{\prime} T_{1}}{2 n}\right)=\left(\frac{Q_{S}^{\prime} T_{1}}{2 n f}\right)=\frac{Q_{M}^{\prime 2}}{2 n f P_{M}},
$$

where $Q^{\prime} s=Q_{M}^{\prime} / f$, and $T_{1}=Q^{\prime}{ }_{M} / P_{M}$.

Therefore, the total cost for the raw material can be expressed as

$$
T C_{I S}=\frac{D_{S}}{Q_{S}^{\prime} / n} C_{0}+\overline{\hat{I}}_{I S} h_{S}=\frac{n D_{S}}{Q_{M}^{\prime}} C_{0}+\frac{Q_{M}^{\prime 2} h_{S}}{2 n f P_{M}},
$$

Where $\frac{Q_{M}^{\prime}}{Q_{s}^{\prime}}=\frac{D_{M}}{D_{S}}=f$.

Therefore, the total cost for this imperfect matching case can be found as

$$
\begin{aligned}
T C_{I}\left(Q_{M}^{\prime}, n\right) & =T C_{I S}+T C_{I M}=\frac{n D_{M}}{Q_{M}^{\prime}} C_{0}+\frac{Q_{M}^{\prime 2} h_{S}}{2 n f P}+\frac{D_{M}}{Q_{M}^{\prime}} C_{S} \\
& +h_{M}\left[\frac{Q_{M}^{\prime}}{2}-\frac{I_{0}}{2 Q_{M}^{\prime}}\left(I_{0}+y-D_{M} T_{S}\right)+\frac{1}{2}\left(4 I_{0}+y-D_{M} T_{S}\right)\right]
\end{aligned}
$$

which yields

$$
\begin{aligned}
T C_{I}\left(Q_{M}^{\prime}, n\right) & =\frac{Q_{M}^{\prime 2} h_{S}}{2 n f P_{M}}+\frac{n D_{M} C_{0}}{Q_{M}^{\prime}}+\frac{1}{2} Q_{M}^{\prime} h_{M} \\
& +\frac{1}{Q_{M}^{\prime}}\left\{D_{M} C_{S}-\frac{I_{0} h_{M}}{2}\left(I_{0}+y-D_{M} T_{S}\right)\right\}+\frac{h_{M}}{2}\left(4 I_{0}+y-D_{M} T_{S}\right) .
\end{aligned}
$$

Replacing the constant term with appropriate notation and simplifying Equation (12), it can be re-written as

$$
T C_{I}\left(Q_{F}^{\prime}, n\right)=B_{1}\left(Q_{M}^{2} / n\right)+B_{2}\left(n / Q_{M}^{\prime}\right)+B_{3} Q_{M}^{\prime}+B_{4} / Q_{M}^{\prime}+B_{5},
$$


where $B_{1}=\frac{h_{S}}{2 f P_{M}}, B_{2}=D_{M} C_{0}, B_{3}=\frac{1}{2} h_{M}, B_{4}=D_{M} C_{S}-\frac{I_{0} h_{M}}{2}\left(I_{0}+y-D_{M} T_{S}\right)$, and, $B_{5}=\frac{h_{M}}{2}\left(4 I_{0}+y-D_{M} T_{S}\right)$.

The total cost function for this part of research is a non-linear integer programming problem with two integer variables $Q_{F}^{\prime}$ and $n$. Let, the problem is defined as IM (imperfect matching). Again, the production quantity $Q_{F}^{\prime}$ and the number of raw material shipment cannot be less than or equal to 1. Hence, the Problem IM can be expressed with two constraints as

Problem IM: Find $m$, and $n$ so as to

Minimize:

$$
T C_{I}\left(Q_{F}^{\prime}, n\right)=B_{1}\left(Q_{M}^{\prime 2} / n\right)+B_{2}\left(n / Q_{M}^{\prime}\right)+B_{3} Q_{M}^{\prime}+B_{4} / Q_{M}^{\prime}+B_{5},
$$

Subject to:

$$
Q_{M}^{\prime} \geq 1
$$

$$
n \geq 1,
$$

$Q_{M}^{\prime}$ and $n$ are integer.

In the following section, the solution procedures for Problem IM are described in details.

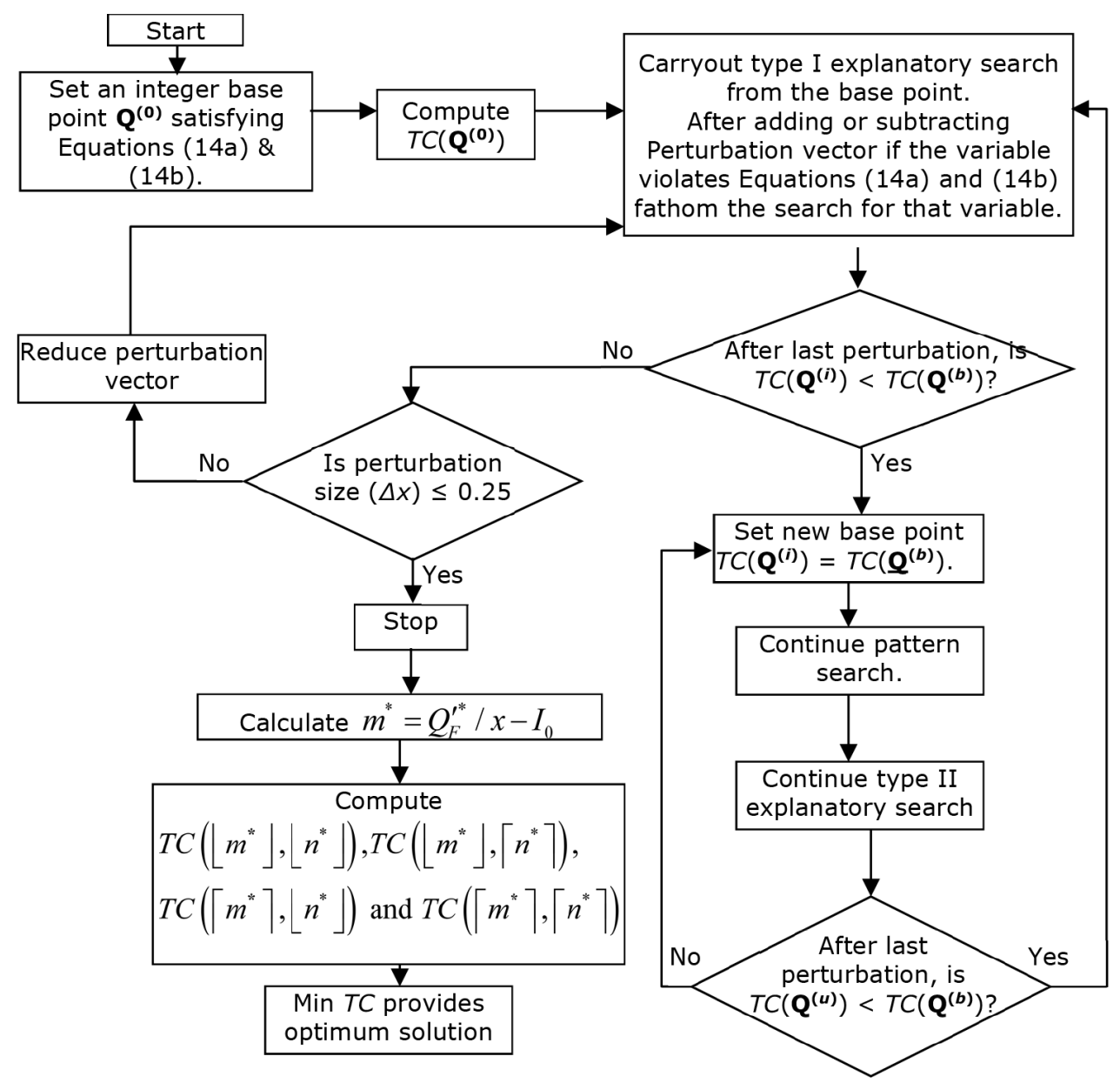

Figure 3. Flow chart of the Modified Hook and Jeeves algorithm 


\subsection{Solution Technique}

The total cost function developed for imperfect matching problem is also a nonlinear integer programming (NLIP) problem and a non-convex function. To find the starting basic solution it is observed that one of the variables have roots of $4^{\text {th }}$ degree polynomial Equation and also the variables are inter depended. Considering these situations, it is found that the Hook and Jeeves (1961) search algorithm is appropriate to solve the problem. The pattern of Hook and Jeeves search technique is a sequential method consisting of two kinds of moves in every step: (a) exploratory and (b) pattern move. The exploratory move is to explore the local behavior of the objective function and the pattern move is taking advantage of the pattern direction. This algorithm is used to solve unconstrained nonlinear programming problem, but the imperfect matching problem is a nonlinear integer programming problem (NLIP) with linear constraints. Therefore, the Hook and Jeeves search algorithm is modified to solve the NLIP with linear constraint as follows:

\subsubsection{Modified Hook and Jeeves Algorithm: Determine the number of orders and shipments}

Step 0: Given $P, D_{F}, x, I_{0}, H_{R}, K_{0}, K_{S}, T_{S}$ and $f$.

Step 1: Find the starting base point $\mathbf{Q}^{(0)}=\left(Q_{F}^{\prime}{ }_{F}^{(0)}, n^{(0)}\right)$ using constraint given by Equations (14a) \& (14b) and define an integer perturbation vector $\mathbf{P}=\Delta_{i}=\left(\Delta Q_{F}^{\prime}, \Delta n\right)$ where $i=Q_{F}^{\prime} \& n$ (as the variables are integer) in each of the coordinate directions.

Step 2: $\quad$ Compute $T C_{I M}=T C\left(\mathbf{Q}^{(0)}\right)$.

Step 3: Choosing each variable in turn an objective function evaluation is made at $\mathbf{Q}_{i}^{(1)}=\left\{\left(Q_{F}^{\prime(0)}+\Delta Q_{F}^{\prime}{ }^{(0)}, n^{(0)}\right)\right.$ or $\left.\left(Q_{F}^{\prime(0)}, n^{(0)}+\Delta n\right)\right\}$ (to satisfy the constraint given in Equation (14a). If $T C\left(\mathbf{Q}_{i}^{(1)}\right)<T C\left(\mathbf{Q}^{(0)}\right)$, set $T C\left(\mathbf{Q}_{i}^{(1)}\right)<T C\left(\mathbf{Q}_{i}^{(0)}\right)$.

Step 4: Using $\mathbf{Q}_{i}^{(1)}$ as current temporary base point to obtain new temporary base point as follows:

$$
\mathbf{Q}_{i}^{(v)}=\left\{\begin{array}{l}
\mathbf{Q}_{i}^{(v)}+\Delta_{i} \text { if } T C^{+}=T C\left(\mathbf{Q}_{i}^{(v)}+\Delta_{i}\right)<T C\left(\mathbf{Q}_{i}^{(1)}\right) \\
\mathbf{Q}_{i}^{(v)}-\Delta_{i} \text { if } T C^{-}=T C\left(\mathbf{Q}_{i}^{(v)}-\Delta_{i}\right)<T C\left(\mathbf{Q}_{i}^{(1)}\right)<T C^{+}=T C\left(\mathbf{Q}_{i}^{(v)}+\Delta_{i}\right) . \\
\mathbf{Q}_{i}^{(v)} \text { if } T C\left(\mathbf{Q}_{i}^{(1)}\right)<\min \left(T C^{+}, T C^{-}\right)
\end{array}\right.
$$

If $\left(\mathbf{Q}_{i}^{(v)}-\Delta_{i}\right)<$ Equation (14a), terminate that search direction for constraint violation. This process of searching for new temporary base point is continued for $v=1,2, \ldots, u(m, n)$ is perturbed to find $\mathbf{Q}_{i}^{(u)}$, call this point as $\mathbf{Q}^{1}$ label this point as Base 1 .

Step 5: If the point $\mathbf{Q}_{i}^{(i)}=\mathbf{Q}_{i}^{(0)}$. The pattern move phase is implemented by reducing the integer perturbation vector $\mathbf{P}=\Delta_{i}=\left(\Delta Q_{F}^{\prime}, \Delta n\right)$ by $\mathbf{P}=\Delta_{i} / 2=\left(\Delta Q_{F}^{\prime} / 2, \Delta n / 2\right)$ where $i=Q_{F}^{\prime}$ and $n$ and go to Step 3 .

Step 6: If $\mathbf{Q}_{i}^{(i)}$ is different from $\mathbf{Q}_{i}^{(0)}$, find a new base point as $\mathbf{Q}^{1}=\mathbf{Q}_{i}^{(0)}+2\left(\mathbf{Q}_{i}^{(k)}-\mathbf{Q}_{i}^{(0)}\right)=2\left(\mathbf{Q}_{i}^{(1)}-\mathbf{Q}_{i}^{(0)}\right.$. Indicate this point as Base 2, and go to Step 3.

Step 7: If at the end of Step $4 T C\left(\mathbf{Q}^{2(u)}\right)<T C\left(\mathbf{Q}_{i}^{2(0)}\right)$, take the new base point as $\mathbf{Q}^{2}=\mathbf{Q}^{2\left({ }^{(i)}\right)}$ and go to Step 6. If $T C\left(\mathbf{Q}_{i}^{2(u)}\right)>T C\left(\mathbf{Q}_{i}^{2(0)}\right)$, set $\mathbf{Q}^{3} \equiv \mathbf{Q}^{2}$ and go to Step 5 .

Step 8: If solution does not improve, stop; that is the optimal solution; otherwise go to Step 5 and continue until

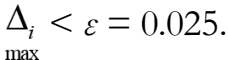

Step 9: Compute $m^{*}=Q_{F}^{* *} / x-I_{0}$. If $\left\lfloor m^{*}\right\rfloor<m^{*}$ and $\left\lfloor n^{*}\right\rfloor<n^{*}$ or $\left\lceil m^{*}\right\rceil>m^{*}$ and $\left\lceil n^{*}\right\rceil>n^{*}$, and compute $T C\left(\left\lfloor m^{*}\right\rfloor,\left\lfloor n^{*}\right\rfloor\right), T C\left(\left\lfloor m^{*}\right\rfloor,\left\lceil n^{*}\right\rceil\right), T C\left(\left\lceil m^{*}\right\rceil,\left\lfloor n^{*}\right\rfloor\right)$ and $T C\left(\left\lceil m^{*}\right\rceil,\left\lceil n^{*}\right\rceil\right)$ and take the smallest $T C$ for optimal solution of integer variables.

The following section represents the numerical computation for six data sets to assess the efficiency of the algorithm described in this section. Otherwise, a random search procedure may be applied to find the local optimal solutions. 


\subsection{Computational Results}

The modified Hook and Jeeves search algorithm is used to solve the imperfect matching problem. Using the same sets of data used in Section 3.5 and the Modified Hook and Jeeves algorithm, the computational results are given below in Table 1:

\begin{tabular}{|c|c|c|c|c|c|c|}
\hline Parameters & Problem 1 & Problem 2 & Problem 3 & Problem 4 & Problem 5 & Problem 6 \\
\hline$P$ (units/year) & 3,600 & 3,600 & 6,000 & 7,000 & 8,000 & 11,000 \\
\hline$D_{M}$ (units/year) & 2,400 & 2,400 & 3,000 & 5,200 & 5,200 & 7,200 \\
\hline$C_{0}(\$ /$ order $)$ & 150 & 100 & 150 & 200 & 200 & 300 \\
\hline$C_{s}(\$ /$ setup $)$ & 50 & 100 & 60 & 70 & 200 & 250 \\
\hline$h_{S}(\$ /$ unit/year $)$ & 1 & 10 & 3.5 & 4 & 4 & 10.5 \\
\hline$h_{M}(\$ /$ unit/year $)$ & 2 & 10 & 5 & 15 & 25 & 45 \\
\hline$f$ & 2 & 3 & 3 & 2.5 & 3 & 4 \\
\hline$y$ (units/shipment) & 100 & 100 & 150 & 200 & 300 & 350 \\
\hline$I_{0}$ & 25 & 30 & 50 & 80 & 90 & 100 \\
\hline$L$ (year/shipment) & 0.04167 & 0.04167 & 0.0500 & 0.03846 & 0.05769 & 0.04861 \\
\hline$T_{s}$ (years) & 0.001 & 0.002 & 0.002 & 0.003 & 0.005 & 0.006 \\
\hline
\end{tabular}

Table 1. Data set for computation of Problem IM

\begin{tabular}{|c|c|c|c|c|c|c|}
\hline Parameters & Problem 1 & Problem 2 & Problem 3 & Problem 4 & Problem 5 & Problem 6 \\
\hline$Q^{*}$ & 660.94 & 295.73 & 483.24 & 405.00 & 364.68 & 367.15 \\
\hline$m^{*}$ & 6.61 & 2.96 & 3.22 & 2.02 & 1.22 & 1.05 \\
\hline$\left\lfloor m^{*}\right\rfloor$ & 6 & 2 & 3 & 2 & 1 & 1 \\
\hline$\left\lceil m^{*}\right\rceil$ & 7 & 3 & 4 & 3 & 2 & 2 \\
\hline$n^{*}$ & 1 & 1 & 1 & 1 & 1 & 1 \\
\hline$T C_{I}^{*}\left(Q_{M}^{\prime}{ }^{*}, n^{*}\right)$ & $\$ 1,610.48$ & $\$ 4,154.74$ & $\$ 3,344.32$ & $\$ 9,914.21$ & $\$ 17,075.31$ & $\$ 32,472.76$ \\
\hline$T C\left\{\left\lfloor m^{*}\right\rfloor, n^{*}\right\}$ & $\$ 1,612.82$ & $\$ 4,255.80$ & $\$ 3,345.81$ & $\$ 10,003.83$ & $\$ 19,010.69$ & $\$ 32,818.16$ \\
\hline$T C\left\{\left\lceil m^{*}\right\rceil, n^{*}\right\}$ & $\$ 1,616.94$ & $\$ 4,174.05$ & $\$ 3,458.00$ & $\$ 10,767.26$ & $\$ 17,096.01$ & $\$ 37,785.24$ \\
\hline$T C_{I}^{*}\left(m^{*}, n^{*}\right)$ & $\$ 1,612.82$ & $\$ 4,174.05$ & $\$ 3,345.81$ & $\$ 10,003.83$ & $\$ 17,096.01$ & $\$ 32,818.16$ \\
\hline
\end{tabular}

Table 2. Results obtained by using modified Hook and Jeeves Algorithm

Using both GAMS and LINGO, the same results (given in Table 2) are found. Hence the solutions for this data set are optimal.

\subsection{Special Case}

As discussed in Section 3, when plant is idle during the downtime period only (Figure 4), the inventory model transforms to the imperfect matching model with idle time.

Therefore, when $T_{S} \rightarrow T_{S}+T_{D}=T_{S}+T_{S}+T_{P}=2 T_{S}+m y / P=2 T_{S}+\left(Q^{\prime}{ }_{M}-I_{0}\right) / P_{M}$, the total cost function expressed in Equation (12) transforms to

$$
\begin{aligned}
T C_{I S}\left(Q_{M}^{\prime}, n\right)=\frac{Q_{M}^{\prime 2} h_{S}}{2 n f P_{M}} & \frac{n D_{M} C_{0}}{Q_{M}^{\prime}}+\frac{1}{Q_{M}^{\prime}}\left\{D_{M} C_{S}-\frac{I_{0} h_{M}}{2}\left(I_{0}+y-2 D_{M} T_{S}\right)\right\} \\
& +\frac{Q_{M}^{\prime} h_{M}}{2}\left(1-\frac{D_{M}}{P_{M}}\right)+\frac{h_{M}}{2}\left\{4 I_{0}+y+D_{M}\left(\frac{I_{0}}{P_{M}}-2 T_{S}\right)\right\} .
\end{aligned}
$$

which is the modified Sarkers and Parija (1994) model. 


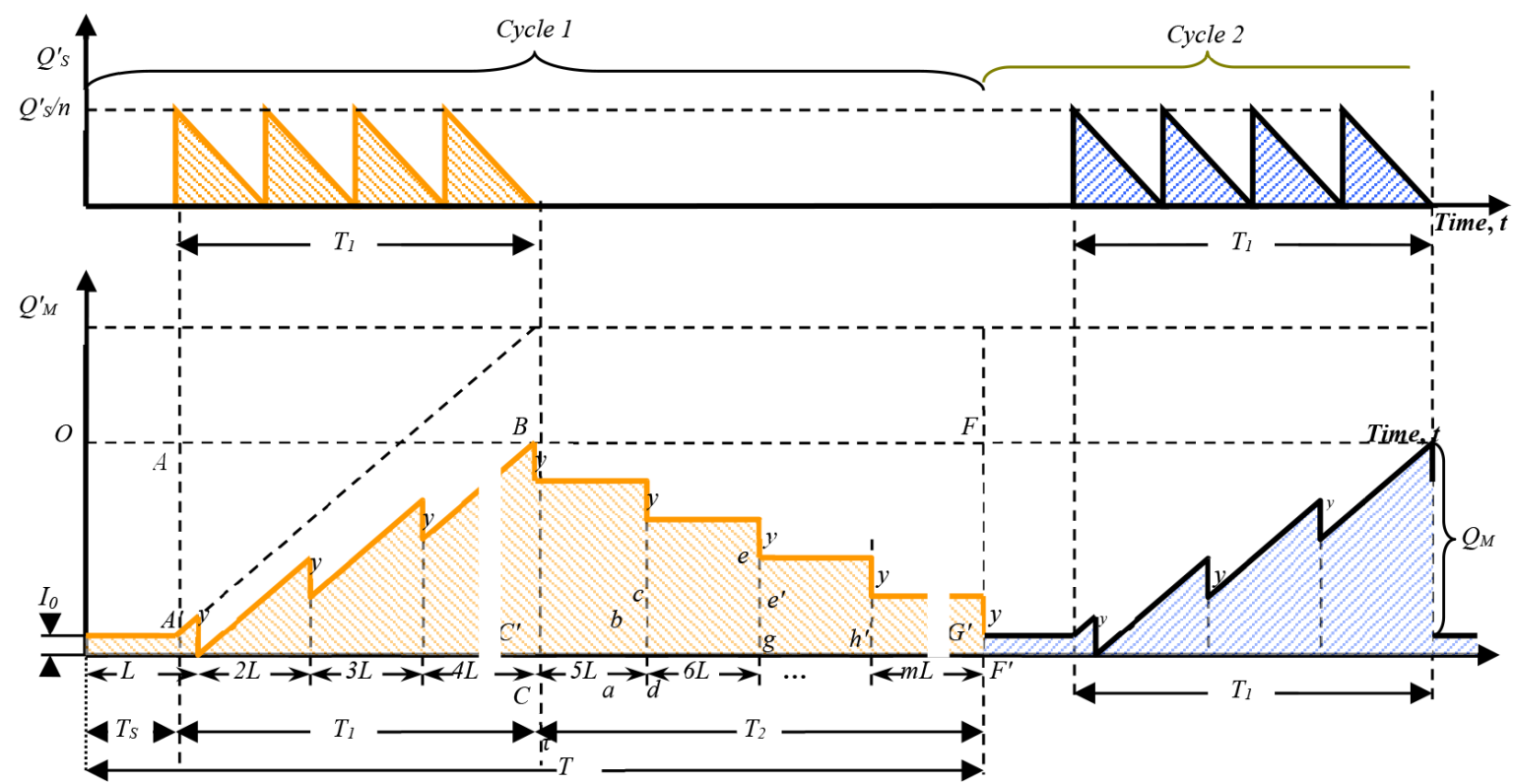

Figure 4. (a) Finished products inventory with idle time; (b) Raw material inventory.

\section{Single Facility Lot Sizing Model}

In a single facility lot sizing model, multiple products are produced in a time span where completion of the production of any product can meet the customers demand during that time span. After the time span the product goes to production again to meet the next time span. This time span is referred as rotational cycle. This section considers a single production facility that produces $K$ products with a constant demand of $D_{M k}$ units per year for product $k$ (where $k=1,2, \ldots, K$ ), and $k$ product is produced at a constant rate of $P_{k}$ units per year to satisfy the demand $D_{M k}$. All products are delivered at a fixed amount of $y_{k}$ units after every $L_{k}$ time units. According to the assumption, production of all $k$ items must meet customers' demand and $\sum_{k=1}^{K}\left(D_{M k} / P_{k}\right) \leq 1$.

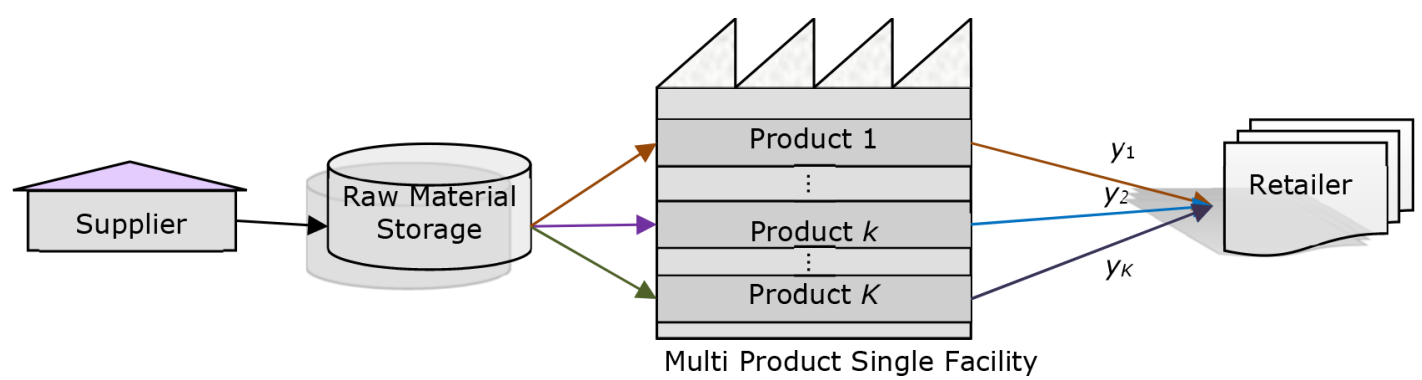

Figure 5. Single-supplier, multi-product and Single-buyer supply chain system

Also, due to rotational cycle policy, all products with the same production cycle time, $T_{C}$, and a lot of each product is produced during this time period. Due to the rotational, the products are produced in a fixed order, which is repeated from cycle to cycle. Without permitting any shortages, it is a problem to determine the time of production and optimum number of units to produce for each item which was defined as rotational cycle by Johnson and Montgomery (1974). In their research they considered a single facility lot sizing model based on classical inventory model. In real life, the single production facility, a number of products are always left-over after the possible deliveries are made. These left-over amounts are added to the next shipment after the production of required amount to make-up a complete batch. An illustration may be observed in retail stores such as Albertson's, Target, Wal-Mart, etc. This research incorporates the inventory model with JIT delivery and imperfect matching inventory situation. 


\subsection{Notation and Assumptions}

The notation used to develop this model are described where used. To develop the mathematical model the assumptions considered are

1. Production rates are constant and finite and greater than the demand rates, $P_{1}>D_{M 1}$,

2. Production of all $\mathrm{K}$ items must meet customers' demand,

3. Production facility considers as just-in-time (JIT) delivery and supply of finished products and raw materials, respectively,

4. Production run of a product starts immediately after the uptime or production run of previous product and setup time,

5. Multiple products are produced in each rotational cycle, and

6. A fixed quantity is left-over after required shipments and carried over to the succeeding cycle.

\subsection{Raw Material Inventory and Cost Function}

To develop the mathematical model the assumptions considered are (a) production rates are constant and finite and greater than the demand rates, $P_{1}>D_{M 1}$, (b) production of all $K$ items must meet customers' demand, (c) production facility considers as just-in-time (JIT) delivery and supply of finished products and raw materials, respectively, (d) production run of a product starts immediately after the uptime or production run of previous product and setup time, (e) multiple products are produced in each rotational cycle, and (f) a fixed quantity is left-over after required shipments and carried over to the succeeding cycle.

An inventory diagram of a single facility lot sizing model is presented in Figure 6. The pattern of raw material inventory is shown in Figure 6(a) where $Q_{S}$ is the raw materials required from the supplier during $T_{P 1}$ time period. These $Q_{s}$ units are ordered in $n_{1}$ batches in instantaneous replenishments of $Q_{S} / n_{1}$ units. It is assumed that each unit of product 1 produced requires $f_{1}$ units of raw material, so that $Q^{\prime}{ }_{M 1}=f_{1} Q_{s}$. Again, in this research the raw materials are ordered and converted to finished goods during the production time or uptime, $T_{P 1}$. Thus, the time weighted inventory, $\bar{I}_{\mathrm{R}}$ of raw material held in a cycle of product 1 is given by

$$
\bar{I}_{S 1}=Q_{S}^{\prime} T_{P 1} /\left(2 n_{1}\right)=Q_{M 1}^{\prime} T_{P 1} /\left(2 n_{1} f_{1}\right)=Q_{M 1}^{\prime 2} /\left(2 n_{1} f_{1} T_{P 1}\right),
$$

Where $Q_{M k}^{\prime} / Q_{s}^{\prime}=D_{M k} / D_{M k}=f_{k}, T_{p k}=Q_{F k}^{\prime} / P_{k}$ and $k=1, \ldots, K$.

Therefore, the total cost for the raw material $k$ can be expressed using Equation (17) as

$$
T C_{S k}=\frac{n_{k} D_{S k} C_{0 k}}{Q_{S}^{\prime}}+\bar{I}_{S k} h_{S}=\frac{n_{k} D_{M k} C_{0 k}}{Q_{M k}^{\prime}}+\frac{Q_{M k}^{\prime 2} h_{S}}{2 n_{k} f_{k} P_{k}} .
$$

\subsection{Finished Goods Inventory and Cost Function}

According to the JIT delivery schedule, fixed amount of $y_{k}$ units of product $k$ will be delivered after every $L_{k}$ time units. The lot size for product $k$ must be equal to the demand during the rotational cycle, $T_{C}$, without permitting shortages as

$$
Q_{M k}^{\prime}=\left(n_{k} y_{k}+I_{0 k}\right)=T_{C} D_{M k} .
$$

According to Figure 6(b), at point $A_{1}$ production of product 1 starts with $P_{1}$ units/year after $T_{S 1}$ time units and produces exactly $Q_{M 1}^{\prime}\left(=n_{1} y_{1}+I_{01}\right)$ amount to deliver $y_{1}$ after $L_{1}$ time units. Hence, during time $L_{1}-T_{S 1}$ time the quantity produced is $x_{1}-I_{01}$ at the rate of $P_{1}$, so that $I_{01}+\left(y_{1}-I_{01}\right) P_{1} \geq y_{1}$. The first shipment of $y_{1}$ units of product 1 can be delivered at point $\mathrm{B}_{1}$ after $L_{1}$ time units combining with the left over inventory of $I_{01}$ from the previous cycle. Again, production continues and the inventory builds up as $P_{1}>D_{F 1}$ and another shipment of $x_{1}$ amount is made at point $C_{1}$ after $L_{1}$ time units. 


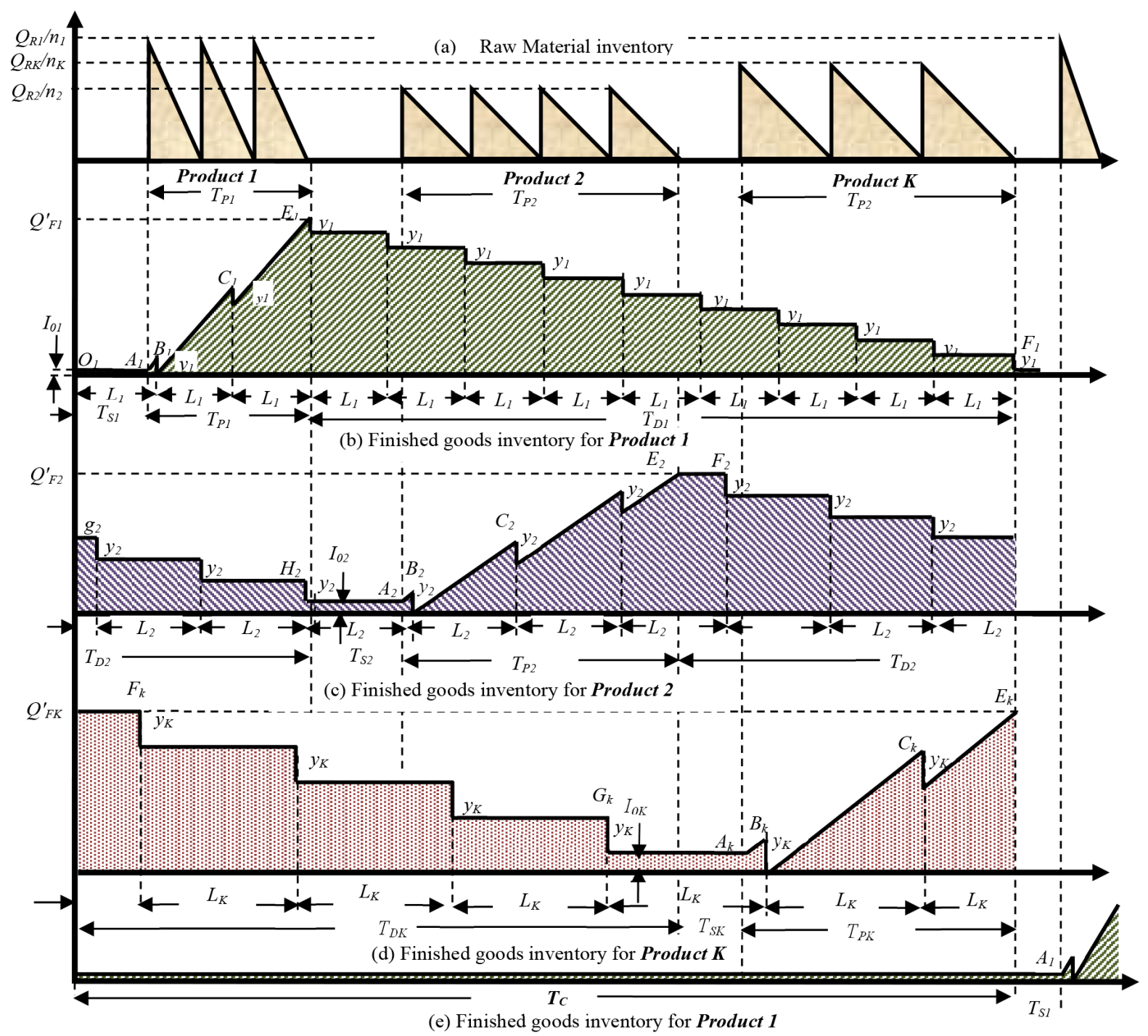

Figure 6. Rotational cycle inventory formation

Thus, after the uptime $T_{P 1}$ and point $E_{1}$, production of product 1 stops and the inventory forms a saw-tooth pattern. After point $E_{1}, y_{1}$ amount is shipped in every $L_{1}$ time units to the customer from built-up inventory during downtime $T_{D 1}$. During downtime $T_{D 1}$, the inventory forms as stair case pattern. At the end of $T_{D 1}$ time and all possible shipments $I_{01}$ amount of inventory left out in the warehouse as $y_{1}>I_{01}$, which is carried over to the next production cycle of product 1 . At the end of $T_{P 1}$ and after $T_{S 2}$, the production of product 2 starts and delivers $y_{2}$ units of product 2 after $L_{2}$ time units [Figure 6(c)]. The production of product 2 continues until $T_{P 2}$ time units followed by the downtime of $T_{D 2}$. Thus, the process continues for product $K$ from point $A_{k}$ to $E_{k}$ according to Figure $6(\mathrm{~d})$. It should be noted that during $T_{P 2}$ and $T_{P K}$, the amount of product 2 and product $K$ produced, respectively, must satisfy customers' demand of these products throughout rotational cycle, $T_{C}$. After $T_{P K}$, the production of product 1 starts again. Figure 6(b) is used to calculate the average on-hand inventory of the finished goods. $I_{T 1}, I_{P 1}$, and $I_{D 1}$ are the total inventory, uptime inventory and downtime inventory for product 1, respectively. Therefore, the total inventory can be calculated as

$$
I_{T 1}=I_{P 1}-I_{D 1}
$$

From Figure 6(b), it can be found that

$$
I_{P}=n_{1} y_{1} T_{P 1} / 2+n_{1} y_{1} T_{D 1}+I_{01} T_{C}
$$


Using Equation (21) upon simplification and the inventory can be found as

$$
I_{P}=Q_{M 1}^{\prime 2}\left[3 /\left(2 D_{M 1}\right)-1 / P_{1}\right]-I_{01} Q_{M 1}^{\prime}\left[1 /\left(2 D_{M 1}\right)-1 / P_{1}\right]+\left(I_{01}-Q_{M 1}^{\prime}\right) T_{S 1}
$$

Again, the total inventory shipped can be calculated from Figure 6(b) as

$$
I_{D}=L_{1} y_{1}+2 L_{1} y_{1}+\ldots+(m-1) L_{1} y_{1}=\frac{m_{1}\left(m_{1}-1\right) L_{1} y_{1}}{2}=\frac{m_{1} y_{1}^{2}\left(m_{1}-1\right)}{2 D_{M 1}},
$$

Where $L_{1}=y_{1} / D_{M 1}$.

Hence, the average inventory for product $1, \hat{I}_{T 1}$, and time period, $T_{C}$, can be calculated by combining and simplifying Equations (21), (22) and (23) as

$$
\begin{aligned}
\hat{I}_{T 1}=\frac{Q_{M 1}^{\prime}}{2 D_{M 1}} & {\left[Q_{M 1}^{\prime}+4 I_{01}+y_{1}-2 D_{M 1} T_{S 1}-\frac{D_{M 1}\left(Q_{M 1}^{\prime}-I_{01}\right)}{P_{1}}\right] } \\
& -\frac{I_{01}}{2 D_{M 1}}\left[I_{01}+y_{1}-2 D_{M 1} T_{S 1}-\frac{D_{M 1}\left(Q_{M 1}^{\prime}-I_{01}\right)^{-}}{P_{1}} .\right.
\end{aligned}
$$

Using Equation (24), the total cost function of product $k$ can be expressed as

$$
\begin{aligned}
T C_{k}\left(Q_{M k}^{\prime}\right)=\frac{1}{Q_{M k}^{\prime}} & \left\{D_{M k} C_{S k}-\frac{I_{0 k} h_{M k}}{2}\left(I_{0 k}+y_{k}-2 D_{M k} T_{S k}\right)\right\} \\
+ & \frac{Q_{M k}^{\prime} h_{M k}}{2}\left(1-D_{M k} / P_{k}\right)+\frac{h_{M k}}{2}\left\{4 I_{0 k}+y_{k}+D_{M k}\left(I_{0 k} / P_{k}-2 T_{S k}\right)\right\}
\end{aligned}
$$

Now, replacing $Q^{\prime}{ }_{M k}$ from Equations (18) and (25) by using the relationship presented in equation (19), the new equations can be expressed as

$$
\begin{gathered}
T C_{S k}=\frac{n_{k} C_{0 k}}{T_{C}}+\frac{h_{S} T_{C}^{2} D_{M k}^{2}}{2 n_{k} f_{k} P_{k}} \text {, and } \\
T C_{k}\left(Q_{M k}^{\prime}\right)=\frac{1}{T_{C} D_{M k}}\left\{D_{M k} C_{S k}-\frac{I_{0 k} h_{M k}}{2}\left(I_{0 k}+y_{k}-2 D_{M k} T_{S k}\right)\right\} \\
+\frac{h_{M k}}{2}\left[T_{C} D_{M k}\left(1-D_{M k} / P_{k}\right)+\left\{4 I_{0 k}+y_{k}+D_{M k}\left(I_{0 k} / P_{k}-2 T_{S k}\right)\right\}\right]
\end{gathered}
$$

Using Equations (26) and (27) and simplifying, the total cost function of finished product $k$ can be expressed as

$$
\begin{aligned}
T C_{k}\left(Q_{M k}^{\prime}, m_{k}\right)= & \frac{T_{C}^{2} D_{M k}^{2} h_{S k}}{2 m_{k} f_{k} P_{k}}+\frac{n_{k} C_{0 k}}{T_{C}}+\frac{T_{C} D_{M k} h_{M k}}{2}\left(1-D_{M k} / P_{k}\right) \\
& +\frac{1}{T_{C}}\left\{C_{S k}-\frac{I_{0 k} h_{M k}}{2 D_{M k}}\left(I_{0 k}+y_{k}-2 D_{M k} T_{S k}\right)\right\}+\frac{h_{M k}}{2}\left\{4 I_{0 k}+y_{k}+D_{M k}\left(I_{0 k} / P_{k}-2 T_{S k}\right)\right\} .
\end{aligned}
$$

\subsection{Objective Functions and its Constraints}

Combining all costs for all $K$ products and using Equation (28), the objective function can be written as

$$
\begin{aligned}
C_{T}\left(T_{C}, m_{1}, \ldots, m_{K}\right) & =\sum_{k=1}^{K} \mid \frac{T_{C}^{2} D_{M k}^{2} h_{S k}}{2 m_{k} f_{k} P_{k}}+\frac{n_{k} C_{0 k}}{T_{C}}+\frac{T_{C} D_{M k} h_{M k k}}{2}\left(1-D_{M k} / P_{k}\right) \\
& +\frac{1}{T_{C}}\left\{C_{S k}-\frac{I_{0 k} h_{M k}}{2 D_{M k}}\left(I_{0 k}+y_{k}-2 D_{M k} T_{S k}\right)\right\}+\frac{h_{M k}}{2}\left\{4 I_{0 k}+y_{k}+D_{M k}\left(I_{0 k} / P_{k}-2 T_{S k}\right)\right\} .
\end{aligned}
$$


Before minimizing the problem, it is necessary to study the constraints related to the rotational cycle policy, such as the setup times the number of raw material deliveries for each product. If the setup time for product $k$ is $T_{S k}$, then the total setup time per cycle and the total production time per cycle must be smaller or equal to the rotational cycle length. Therefore, the following constraint on $T_{C}$ will be

$$
T_{C} \geq \sum_{k=1}^{K}\left[T_{S k}+Q_{M k}^{\prime} / P_{k}\right]
$$

Replacing $Q^{\prime}{ }_{M k}$, by using Equation (19), it can be re-written as

$$
T_{C} \geq \sum_{k=1}^{K} \frac{T_{S k}}{1-\sum_{k=1}^{K}\left[D_{M k} / P_{k}\right]} \equiv T_{\min } \geq 0
$$

Also, the number of raw material delivery, $n_{k}$ for product $k$ cannot be less than 1 and should be an integer variable. Hence, the constraint on $n_{k}$ is

$$
n_{k} \geq 1 \text { and is an integer, } \quad \text { for } k=1,2, \ldots, K
$$

Using these two constraints defined in Equations (31) and (32), the objective function can be formulated as

Minimize:

$$
\begin{aligned}
C_{T}\left(T_{C}, n_{1}, \ldots, n_{K}\right)=\sum_{k=1}^{K}\left[\frac{T_{C}^{2} D_{M k}^{2} h_{S k}}{2 m_{k} f_{k} P_{k}}+\frac{n_{k} C_{0 k}}{T_{C}}+\frac{T_{C} D_{M k} h_{M k}}{2}\left(1-D_{M k} / P_{k}\right)\right. \\
+\frac{1}{T_{C}}\left\{C_{S k}-\frac{I_{0 k} h_{M k}}{2 D_{M k}}\left(I_{0 k}+y_{k}-2 D_{M k} T_{S k}\right)\right\}+\frac{h_{M k}}{2}\left\{4 I_{0 k}+y_{k}+D_{M k}\left(I_{0 k} / P_{k}-2 T_{S k}\right)\right\},
\end{aligned}
$$

Subject to:

$$
\begin{gathered}
T_{C} \geq T_{\min } \geq 0, \\
n_{k} \geq 1 \text { and is an integer, } \quad \text { for } k=1,2, \ldots, K .
\end{gathered}
$$

Therefore, the problem becomes a mixed integer non-linear programming problem and the solution procedure to this problem is discussed in the next section.

\subsection{Solution Technique of Rotational Cycle Problem}

The formulation of the single facility lot-sizing problem for imperfect matching system can be categorized as a mixed-integer non linear programming problem where $m_{k}$ 's are integer and $T_{C}$ is a real variable and the number of variables are $(K+1)$. Due to formulation of the problem, it cannot be solved using derivatives and a closed form solution cannot be determined. Using the Divide and Conquer rule, the objective function is divided into two parts (a) rotational cycle for finished products, and (b) number of raw material orders. The rotational cycle for the finished products $\left(T_{C}\right)$ is the same for the raw material delivery, because the raw materials are delivered from the supplier by instantaneous replenishments. Again, the raw material for a product $k$ is ordered when the finished product $k$ goes in production. The solution procedures are shown as follows:

\section{(a) Rotational Cycle for Finished Products}

To solve the rotational cycle policy for the part finished product supply, the cost function from Equation (27) can be written as

Minimize: 


$$
\begin{aligned}
C_{M}\left(Q_{M k}^{\prime}\right)=\frac{1}{T_{C} D_{M k}} & \left\{D_{M k} C_{S k}-\frac{I_{0 k} h_{M k}}{2}\left(I_{0 k}+y_{k}-2 D_{M k} T_{S k}\right)\right\} \\
+ & \frac{h_{M k}}{2}\left[T_{C} D_{M k}\left(1-D_{M k} / P_{k}\right)+\left\{4 I_{0 k}+y_{k}+D_{M k}\left(I_{0 k} / P_{k}-2 T_{S k}\right)\right\}_{-}^{-}\right.
\end{aligned}
$$

Subject to:

$$
T_{C} \geq T_{\min } \geq 0
$$

It can be shown that the Equation (34) is a convex function for $T_{C}$; therefore, it can be solved by differentiation with respect to $T_{C}$ and equate it to zero, which yields

$$
T_{C}^{*}=\sqrt{\frac{2 \sum_{k=1}^{K}\left[C_{S k}-I_{0 k} h_{M k}\left(I_{0 k}+y_{k}-2 D_{M k} T_{S k}\right) /\left(2 D_{M k}\right)\right]}{\sum_{k=1}^{K} D_{M k} h_{M k}\left(1-D_{M k} / P_{k}\right)}},
$$

where $k=1, \ldots, K$.

Equation (35) has to satisfy the constraint given in Equation (34a). Using the optimal rotational cycle $T_{C}^{*}$, the number of shipments for different finished product can be obtained from Equation (19). The optimal rotational cycle, $T^{*}{ }_{C}$ is used to solve the optimal number of orders for raw materials in following section.

\section{(b) Number of Raw Material Orders}

As the raw materials order policy is instantaneous, the production rate for the raw material is $\infty$; therefore, this also satisfies the condition for rotational cycle. Now, applying the value of $T_{C}^{*}$ from Equation (35), the total cost/objective function for raw material $k$ can be written as [from Equation (26)]

Minimize:

$$
C_{R}\left(n_{k}\right)=\frac{n_{k} C_{0 k}}{T_{C}^{*}}+\frac{T_{C}^{* 2} D_{F k}^{2} h_{S k}}{2 n_{k} f_{k} P_{k}},
$$

Subject to:

$$
n_{k} \geq 1 \text { and integer, } \forall k=1, \ldots, K \text {. }
$$

This objective function [Equation (36)] is convex in $n_{k}$ and the objective function is a discrete function, which cannot be solved using differentiation. Hence, the induction method is used to solve $n_{k}$. Using the induction method in Equation (36), the boundary condition for $n_{k}^{*}$ is can be evaluated as

$$
\left\lceil\left[\sqrt{1+4 \Delta_{k}}-1\right] / 2\right\rceil \leq n_{k}^{*} \leq\left\lfloor\left[\sqrt{1+4 \Delta_{k}}+1\right] / 2\right\rfloor,
$$

Where $\Delta_{k}=\frac{h_{M k} T_{C}^{* 3} D_{M k}^{2}}{2 f_{k} P_{k} K_{0 k}}$ and $k=1,2, \ldots, K$. In addition, Equation (37) has to satisfy the constraint given in Equation (36a). Applying the boundary condition in Equation (37) the optimal objective function can be evaluated as well as the optimum number of orders $m_{k}^{*}$ for raw material $k$, where $k=1, \ldots, K$. Hence, optimum total cost for all raw materials can be expressed as

$$
C_{R}\left(n_{1}^{*}, \ldots, n_{K}^{*}\right)=\sum_{k=1}^{K}\left[\frac{n_{k}^{*} C_{0 k}}{T_{C}^{*}}+\frac{T_{C}^{* 2} D_{M k}^{2} h_{S k}}{2 n_{k}^{*} f_{k} P_{k}}\right.
$$


As discussed before, both $n_{k}^{*}$ and $T_{C}^{*}$ is may not be globally optimal. Therefore, another forward search is conducted using Equation (33), starting from the constraints for $T^{*}{ }_{C}$ and $n_{k}^{*}$ [given in Equations (33a) and (33b)] and with step sizes 0.01 and 1 , respectively, to evaluate the optimal $T^{T^{p t}}{ }_{C}$ and $n^{o p t}{ }_{k}$ that will minimize the $C_{T}\left(T^{p t}{ }_{C}\right.$, $\left.n^{o p t}, \ldots, n_{k}^{o p t}\right)$.

\subsection{Numerical Computation of Optimum Rotational Cycle}

Six products, presented in Table 3, are being produced in a single facility manufacturing system with JIT delivery.

\begin{tabular}{|c|c|c|c|c|c|c|}
\hline Parameters & Product 1 & Product 2 & Product 3 & Product 4 & Product 5 & Product 6 \\
\hline$P$ (units/year) & 14,000 & 10,500 & 15,000 & 10,000 & 9,000 & 20,000 \\
\hline$D_{F}$ (units/year) & 2,000 & 1,500 & 3,000 & 1,800 & 1,200 & 2,200 \\
\hline$K_{0}(\$ /$ order $)$ & 150 & 100 & 150 & 200 & 200 & 300 \\
\hline$K_{S}(\$ /$ setup $)$ & 50 & 100 & 120 & 130 & 200 & 150 \\
\hline$H_{R}(\$ /$ unit/year $)$ & 1 & 10 & 3.5 & 4 & 4 & 10.5 \\
\hline$H_{F}$ (\$/unit/year) & 2 & 10 & 5 & 15 & 25 & 45 \\
\hline$f$ & 2 & 3 & 3 & 2.5 & 3 & 4 \\
\hline$x$ (units) & 100 & 100 & 150 & 200 & 300 & 350 \\
\hline$I_{0}$ (units) & 25 & 30 & 50 & 40 & 60 & 55 \\
\hline$T_{s}$ (years) & 0.001 & 0.002 & 0.002 & 0.003 & 0.005 & 0.006 \\
\hline
\end{tabular}

Table 3. Data set for single facility lot-sizing model

Using these data from Table 3 and Equation (35), the $T^{*}{ }_{C}$ can be found as $T^{*}{ }_{C}=0.56$ years. Now using the value of $T_{C}^{*}$ in Equation (37) the boundary conditions for $n_{k}^{*}$ can be found as $n_{1}^{*}=1, n_{2}^{*}=1, n_{3}^{*}=1, n_{4}^{*}=1, n_{5}^{*}=1$, and $n^{*}{ }_{6}=1$ Using these values the total costs can be found as $C_{T}\left(T^{*}{ }_{C}, n^{*}{ }_{1}, \ldots, n_{6}^{*}\right)=(0.56,1,1,1,1,1,1)=\$ 33,928.26$ per year, and this is local optimum solution. Therefore, a forward search is conducted starting from $T_{C}^{*}=0.21$ (with step size 0.01), and $m_{k}^{*}=1$ (with step size 1) and the optimum solution is obtained in $C_{T}\left(T^{p \phi t}{ }_{C}, n^{\rho p t}{ }_{1}, n^{\rho \phi t}{ }_{2}, n^{o p t}{ }_{3}, n^{\rho p t}{ }_{4}\right.$, $\left.\left.n^{o p t_{5}}, n_{6}^{\text {opt }}{ }_{6}\right)=0.32,1,1,1,1,1,1\right)=\$ 32,373.85$ per year. The detailed results of rotational cycle policy are presented with numerical values in Table 2 . In this case, it is considered that all six products are produced in a single facility in a sequence and they will be delivered using just-in-time (JIT) policy. Also, the raw materials for each product will be ordered following multiple ordering policies. According to the constraint given in Equations (35a) it can be determined by using the data given in Table 3 that $T_{C} \geq 0.019 / 0.09=0.21$. Also, it is observed that $\sum_{k=1}^{6}\left(D_{M k} / P_{k}\right)=$ $0.91 \leq 1$ which satisfies the assumption for rotational cycle policy. The results for the single facility lot sizing models for imperfect matching case presented in Table 2.

\begin{tabular}{|c|c|c|c|c|c|c|}
\hline Parameters & Product 1 & Product 2 & Product 3 & Product 4 & Product 5 & Product 6 \\
\hline$T_{C}^{*}$, years & \multicolumn{6}{|c|}{0.32} \\
\hline$m_{k}^{*}$ & 1 & 2 & 2 & 1 & 1 & 1 \\
\hline$n^{*}$ & 6 & 4 & 6 & 2 & 1 & 1 \\
\hline$Q_{F k}^{\prime *}$, units/year & 600 & 400 & 900 & 400 & 300 & 350 \\
\hline$Q_{R k, \text { units/year }}^{*}$ & 300 & 133 & 300 & 160 & 100 & 88 \\
\hline$C_{T}^{*}\left(T_{C}^{*}, m_{1}^{*}, \ldots, m_{k}^{*}\right)$ & \multicolumn{6}{|c|}{$\$ 32,373.85$} \\
\hline
\end{tabular}

Table 4. Optimum results for raw materials of imperfect matching case 
Thus, this section concludes the research for rotational cycle policy of an imperfect matching situation when the system idle time is negligible.

\section{Conclusion}

In the past, researchers tried to develop the proper supply chain management with ideal conditions. This research more focused on real life situations where the production facility does not remain idle for longer period of time and does not become empty at the end of full shipments. In many industries, the production facilities stay idle only during the routine maintenance because of high costs to shut down and restarts the production facilities, such as refineries. This research will have a significant impact on the real life production facilities where the idle time of the facility is negligible. Also, this will help to develop a better supply chain management to any industry.

Also, the research extended incorporating an operation policy of a supply chain of a single facility lot-sizing model with just-in-time (JIT) deliveries with imperfect matching situations. Also, the current research considered a supply chain system that operates under a reduced idle time, where the production of a cycle of one product starts immediately after the end of production cycle of previous product. A set of problems are categorized as a serial system with a fixed quantity and a fixed delivery interval. The problem is solved for the optimum rotational cycle, optimum number of orders, optimum batch sizes, and optimum numbers of shipment evaluated to minimize the total system cost.

The operation policies prescribe the number of orders and the ordered quantities of raw materials from suppliers, production quantities, and number of shipments to the customers for an infinite planning horizon. Prospective research issues that can be pursued further concerning the supply chain system addressed in this research by incorporating time varying demand, variable production capacity and rate, transportation costs, and multi-stage systems.

\section{Declaration of Conflicting Interests}

The authors declared no potential conflicts of interest with respect to the research, authorship, and/or publication of this article.

\section{Funding}

The authors received no financial support for the research, authorship, and/or publication of this article.

\section{References}

Biswas, P., \& Sarker, B.R. (2005). Economic order quantity for a JIT production system with minimal downtime. The Proceedings of the Industrial Engineering and Research Conference (CD-ROM), Atlanta, GA, May 14-18, 2005.

Chen, Z.X., \& Sarker, B.R. (2010). Multi-vendor integrated procurement-production system under shared transportation and just-in-time delivery system. Journal of the Operational Research Society, 61(11), 1654-1666. https://doi.org/10.1057/jors.2009.115

Chiu, H.N., \& Huang, H.L. (2003). A multi-echelon integrated JIT inventory model using the time buffer and emergency borrowing policies to deal with random delivery lead times. International Journal of Production Research, 41(13), 2911-2931. https://doi.org/10.1080/0020754031000101303

Diponegoro, A., \& Sarker, B.R. (2002). Determining manufacturing batch sizes for a lumpy delivery system with trend demand. International Journal of Production Economics, 77(2), 131-143. https://doi.org/10.1016/S09255273(02)00108-1

Diponegoro, A., \& Sarker, B.R. (2006). Finite horizon planning for a production system with permitted shortage and fixed-interval deliveries. Computers \& Operations Research, 33(8), 2387-2404.

https://doi.org/10.1016/j.cor.2005.02.019

Diponegoro, A., \& Sarker, B.R. (2007). Operations policy for a supply chain system with fixed interval delivery and linear demand. Journal of the Operational Research Society, 58(7), 901-910. https://doi.org/10.1057/palgrave.jors.2602199 
Fandel, G., \& Trockel, J. (2016). Investment and lot size planning in a supply chain: coordinating a just-in-time-delivery with a Harris- or a Wagner/Whitin-solution. Journal of Business Economics, 86, 173-195. https://doi.org/10.1007/s11573-015-0800-6

Golhar, D.Y., \& Sarker, B.R. (1992). Economic manufacturing quantity in a just in time delivery system. International Journal of Production Research, 30(5), 961-972. https://doi.org/10.1080/00207549208942936

Hill, R.M. (1996). Optimizing a production system with a fixed delivery schedule. Journal of Operational Research Society, 47(7), 954-960. https://doi.org/10.1057/jors.1996.121

Hook, R., \& Jeeves, T.A. (1961). Direct Search Solution of Numerical and Statistical Problems. Journal of the Association for Computing Machinery, 8(April), 212-221. https://doi.org/10.1145/321062.321069

Hoque, M.A. (2009). An alternative optimal solution technique for a single-vendor single-buyer integrated production inventory model. International Journal of Production Research, 47(15), 4063-4076. https://doi.org/10.1080/00207540801905478

Hoque, M.A. (2011). An alternative optimal solution technique for a single-vendor single-buyer integrated production inventory model. International Journal of Production Economics, 131(1), 463-472. https://doi.org/10.1016/j.ijpe.2011.01.006

Jha, J.K., \& Shanker, K. (2009). A single-vendor single-buyer production-inventory model with controllable lead time and service level constraint for decaying items. International Journal of Production Research, 47(24), 6875-6898. https://doi.org/10.1080/00207540802398053

Johnson, L.A., \& Montgomery, D.C. (1974). Operations Research in Production Planning, Scheduling and Inventory Control (first ed.). New York, USA: John Wiley and Sons, Inc.

Jonrinaldi, \& Zhang, D.Z. (2013). An integrated production and inventory model for a whole manufacturing supply chain involving reverse logistics with finite horizon period. Omega-The International Journal of Management Science, 41(3), 598-620. https://doi.org/10.1016/j.omega.2012.07.001

Khan, L.R., \& Sarker, R.A. (2002). An optimal Batch size for a JIT manufacturing system. Computers and Industrial Engineering, 42(2-4), 127-138. https://doi.org/10.1016/S0360-8352(02)00009-8

Kim, S.C., \& Shin, K.S. (2019). Negotiation Model for Optimal Replenishment Planning Considering Defects under the VMI and JIT Environment. The Asian Journal of Shipping and Logistics, 35(3), 147-153. https://doi.org/10.1016/j.ajsl.2019.09.003

Kim, S.L., Banerjee, A., \& Burton, J. (2008). Production and delivery policies for enhanced supply chain partnerships. International Journal of Production Research, 46(22), 6207-6229. https://doi.org/10.1080/00207540701472124

Kim, T., Hong, Y., \& Lee, J. (2005). Joint economic production allocation and ordering policies in a supply chain consisting of multiple plants and a single retailer. International Journal of Production Research, 43(17), 3619-3632. https://doi.org/10.1080/00207540500140831

Mansouri, S.A., Gallear, D., \& Askariazad, M.H. (2012). Decision support for build-to-order supply chain management through multiobjective optimization. International Journal of Production Economics, 135(1), 24-36. https://doi.org/10.1016/j.ijpe.2010.11.016

Mardani, A., Kannan, D., Hooker, R.E., Ozkul, S., Alrasheedi, M., \& Tirkolaee, E.B. (2020). Evaluation of green and sustainable supply chain management using structural equation modelling: A systematic review of the state of the art literature and recommendations for future research. Journal of Cleaner Production, 249 (10 March). https://doi.org/10.1016/j.jclepro.2019.119383

Modak, N.M., Panda, S., \& Sana, S.S. (2015). Optimal just-in-time buffer inventory for preventive maintenance with imperfect quality items. Tékhne, 13(2), 135-144. https://doi.org/10.1016/j.tekhne.2016.02.002 
Mungan, D., Yu, J., \& Sarker, B.R. (2010). Manufacturing lot-sizing, procurement and delivery schedules over a finite planning horizon. International Journal of Production Research, 48(12), 3619-3636.

https://doi.org/10.1080/00207540902878228

Nobil, A.H., Sedigh, A.H.A., \& Cárdenas-Barrón, L.E. (2020). A multiproduct single machine economic production quantity (EPQ) inventory model with discrete delivery order, joint production policy and budget constraints. Annals of Operations Research, 286, 265-301. https://doi.org/10.1007/s10479-017-2650-9

Omar, M., \& Sarker, R. (2015). An optimal policy for a just-in-time integrated manufacturing system for time-varying demand process. Applied Mathematical Modelling, 39, 5327-5329.

https://doi.org/10.1016/j.apm.2015.03.041

Parija, G.R., \& Sarker, B.R. (1999). Operations planning in a supply chain system with fixed-interval deliveries of finished goods to multiple customers. IIE Transactions, 31, 1075-1082. https://doi.org/10.1023/A:1007627609518

Sana, S.S. (2012). A collaborating inventory model in a supply chain. Economic Modelling, 29(5), 2016-2023. https://doi.org/10.1016/j.econmod.2012.04.021

Sarker, B.R., \& Diponegoro, A. (2006). A finite horizon planning with fixed interval of deliveries and no shortage, OPSEARCH, 43(4), 404-424. https://doi.org/10.1007/BF03398786

Sarker, B.R., \& Diponegoro, A. (2009). Optimal production plans and shipment schedules in a supply-chain system with multiple suppliers and multiple buyers. European Journal of Operational Research, 194(3), 753-773. https://doi.org/10.1016/j.ejor.2008.01.025

Sarker, B.R., \& Parija, G.R. (1994). An optimal batch size for a production system operating under a fixed-quantity, periodic delivery policy. Journal of Operational Research Society, 45(8), 891-900. https://doi.org/10.1057/jors.1994.141

Sarker, R.A., \& Khan, L.R. (1999). An optimal batch size for a production system operating under periodic delivery policy. Computers and Industrial Engineering, 37(4), 711-730. https://doi.org/10.1016/S0360-8352(00)00006-1

Torkabadi, A.M., \& Mayorga, R.V. (2017). Implementation of Just-In-Time Policies in Supply Chain Management. International Journal of Economics and Management Systems, 2, 315-320.

Wang, S., \& Ye, B. (2018). A comparison between just-in-time and economic order quantity models with carbon emissions. Journal of Cleaner Production, 187(20 June), 662-671. https://doi.org/10.1016/j.jclepro.2018.03.218

Journal of Industrial Engineering and Management, 2020 (www.jiem.org)

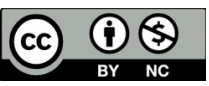

Article's contents are provided on an Attribution-Non Commercial 4.0 Creative commons International License. Readers are allowed to copy, distribute and communicate article's contents, provided the author's and Journal of Industrial Engineering and Management's names are included. It must not be used for commercial purposes. To see the complete license contents, please visit https://creativecommons.org/licenses/by-nc/4.0/. 